Article

\title{
A Field Study on the Impacts of Implementing Concepts and Elements of Industry 4.0 in the Biopharmaceutical Sector
}

\author{
Felipe Silva *(D), David Resende $(\mathbb{D}$, Marlene Amorim $(\mathbb{D}$ and Monique Borges \\ Governance, Competitiveness and Public Policies, Competitiveness and Public Policies, Aveiro University, \\ 3810-193 Aveiro, Portugal; david@ua.pt (D.R.); mamorim@ua.pt (M.A.); monique@ua.pt (M.B.) \\ * Correspondence: felipe.silva@ua.pt
}

Received: 3 September 2020; Accepted: 30 November 2020; Published: 3 December 2020

\begin{abstract}
This study proposes a field study, based on a literature review, about the applications and impacts of Industry 4.0 (I4.0) in the biopharmaceutical sector. The world is facing a new industrial revolution and the central idea is the integration between the virtual and the real world through elements that will allow for a greater degree of automation and digitization of processes. The production of medicines via biological processes is a booming domain in the pharmaceutical sector, that involves extraordinary technological challenges. The fieldwork, carried out between August 2019 and February 2020, involved semi-structured interviews with managers of pharmaceutical companies and specialists in the I4.0 theme. The interviews allowed for the identification of trends and key benefits and barriers for implementing I4.0 in the biopharmaceutical sector. While the perceptions were considerably diversified, benefits in productivity, competitiveness and quality ranked among the most scored items. The main barriers, highlighted by the interviewees, refer to the need to break organizational cultural standards, the regulatory requirements, the lack of organizational strategies for implementation, and the lack of qualified professionals. This work offers a contribution to the biopharmaceutical sector and reinforces the imminent need for companies to adapt to this new reality.
\end{abstract}

Keywords: Industry 4.0; Pharma 4.0; Biopharma 4.0; Bio 4.0

\section{Introduction}

The terms "advanced manufacturing" or "industry 4.0" (I4.0) have been widely cited in the general literature and are directly related to the future of manufacturing and the pursuit of industrial competitiveness. The world is facing a new industrial revolution, evolving at a faster pace than the previous ones. It is characterized by the fusion or integration between the virtual and the real world through elements enabling a greater degree of automation and digitization of processes (see Figure 1). The concept of I4.0 is rooted on a project developed within the high-tech strategy of the German government, towards the automation and digitization of the manufacturing industry [1].

The concepts associated with I4.0 are still at an early stage of development and consolidation. As such, any attempt to classify their elements becomes complex. Despite the existing dispersion of experiences that are emerging related with I4.0, some consensus has already been established about some fundamental elements that underlie the notion of I4.0, including CPS (Cyber-Physical Systems) and IoT (Internet of Things). The technologies that support the implementation of I4.0 are defined as structuring elements, and refer to domains such as automation, Machine to Machine Communication (M2M), artificial intelligence (AI), Big Data analytics, cloud computing, systems integration, and cybersecurity. Other elements, labelled as complementary, are not mandatory across all I4.0 applications, but have been acknowledged for its ability to expand the opportunities for it. These include: 3D printing, 
RFID tag, QR code, augmented reality and virtual reality, among others [2,3]. The adoption of I4.0 technologies is associated with an ample range of benefits, as well as with extraordinary barriers and implementation challenges. A key concern refers to the new requirements and roles that will be asked from professionals, in order to operate in production systems of a high degree of automation. Many companies will find it very difficult to adapt to this new scenario [4].

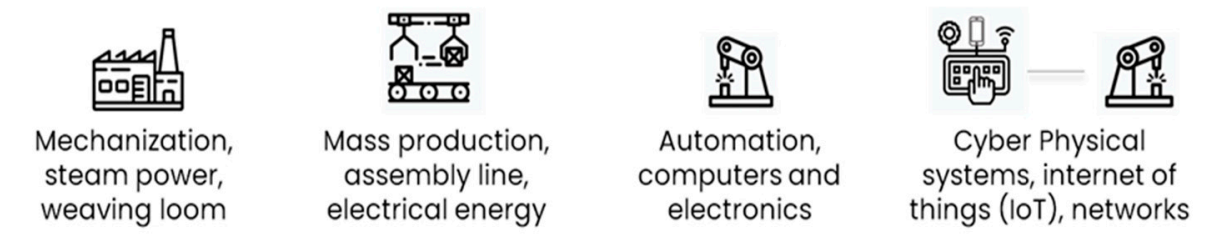

1784

1870

1969

Today

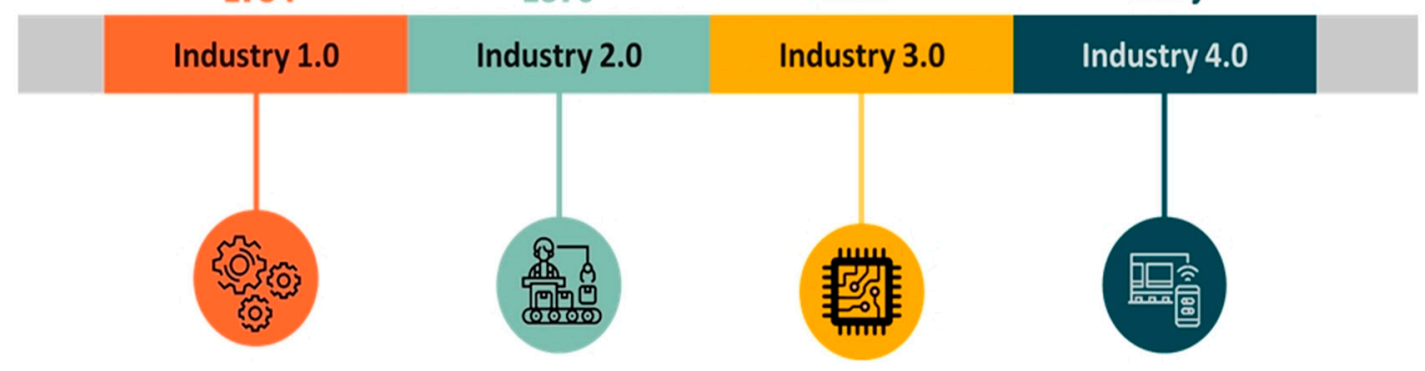

Figure 1. Industry 4.0—Fourth Industrial Revolution (self-elaboration).

The technology diffusion progress embedded in the fourth industrial revolution is expected to grow exponentially in terms of technical change and socioeconomic impact [5]. Indeed, the authors remind that the previous three industrial revolutions seem to fail in the interaction between technological innovation and social innovation. Within the transition to Industry 4.0, industrial transformation enhances the cooperation between consumer and producer, acknowledging the benefit of their interaction on the production and consumption processes. Institutions, technology, and innovation share the same stage. As Lee et al. (2018) systematize numerous definitions of the fourth industrial revolution are proposed, and cover a diversified array of approaches: advanced manufacturing partnership 2.0 (USA), industry 4.0 (Germany), revitalization/robotics strategy (Japan), and manufacturing innovation 3.0 (South Korea) [6].

In the biopharmaceutical sector, the implementation of I4.0 technologies and principles offer opportunities for important gains in the development, production, and availability of biomedicines. The concepts and elements of I4.0 are expected to enable a series of technological innovations, incremental improvements and practical solutions for direct implementation both in the management of the production of biomedicines and in the production processes themselves. Medicines of biological origin began to play an important and increasing role following the Second World War. Nowadays the investments in the development and innovation continue to migrate from the production of pharmaceutical chemicals to the development of biological alternatives. According to Rader and Langer (2018), the growth in revenue from biopharmaceutical products is in the range of $10 \%$ to $15 \%$ per year. Estimates show that this market is growing twice as fast as the pharmaceuticals [7]. The production of biomedicines builds on technological platforms that involve the use of living, attenuated or inactivated organisms, as a whole or in subunits, genetically modified or not, in order to produce vaccines or others medicines of biological origin. These production systems involve expensive, complex, and sophisticated activities that include cell culture, high performance purification systems, strict monitoring through extremely sensitive quality control procedures, among others [8].

The objective of this study was to conduct a field research, building on a previous literature review, on the main trends-including benefits and barriers-associated with the introduction of I4.0 for the 
production of biological medicines. To this end, the study was set up to address the following research question to be answered:

"What are the main benefits and the main barriers and risks associated with the implementation of the concepts and elements of I4.0 in the production of biomedicines?"

The transition to I4.0 is perceived as a paradigm shift, a change of enormous dimensions like what was experienced with the previous industrial revolutions. As such, the effective implementation of many of the projected changes in the production systems is far from being obvious or simple. Industries are required to transform their processes, practices and facilities and equipment, and, in order to support this, to also do an enormous job in re-skilling their professionals and in recruiting new ones equipped to handle new technologies and work process [9]. Recent research suggests that while many companies are not fully ready for an integral transformation, they are keen towards the introduction of some new technologies, and process changes. Some studies highlight the importance of the resistance to change in employees and middle management [10]. Other barriers cited in the literature include insufficient knowledge about the technologies and about the strategic importance of 4.0, as well as concerns with the lack of qualified staff and with the extensive implementation costs [11]. Therefore, the decision towards moving on with I4.0 depends on multiple factors, including the availability of qualified staff, their expertise, company resources, and vision towards the cost as benefits of the change. Several studies are putting forward concerning the barriers and potential benefits from I4.0. Many of these studies offer insights that apply to industries in general. Some are also highlighting some specificities for particular business settings such as the case with small and medium companies. The advancement in studies about how to trigger the implementation of I4.0 is therefore timely and relevant, and the development of knowledge in this field can be very important to establish standard practices to mitigate common difficulties. This study sets up to offer new insights and forward the research agenda on the implementation of I4.0 in the specific sector of biopharma.

\section{Materials and Methods}

The elaborated methodology is exhibited in Figure 2, and further detailed as follows. The study builds on a preliminary review of the literature addressing the main scientific databases and specialized journals in the areas of health, drug production and management of biopharmaceutical companies. The search results returned very few relevant studies addressing the theme of I4.0 in the specific context of biopharmaceutical industry. In total 8 were identified via the traditional scientific bases-Emerald, Scopus and Science Direct-and 35 other manuscripts in specialized journals in the field. Despite the scarcity of specialized literature in this business sector, the analysis allowed for the identification of I4.0 dimensions that supported the subsequent research work, notably the field interviews that were conducted.

The conduction of the fieldwork was supported by prevalent methodological guidelines, including the definition of criteria for delimiting the identification and selection of relevant interviewees, that could contribute with complementary views to the study topic. The criteria considered for this sample selection included aspects such as the level of experience of the interviewee in the biopharmaceutical sector, the familiarity and experience with I4.0 the nature of the corporate or strategic position of the respondent and their familiarity and experience with organizations involved in the production of biomedicines. Prior to the interview the interviewees were offered detailed information about the domain, the purpose, and the methods of the research work.

In total 10 semi-structured interviews were carried out with professionals holding managerial positions in biopharmaceutical industries (six managers) and with I4.0 specialists (four experts) from different countries. Interviews were conducted from August 2019 until February 2020 (see details in Table 1). In the semi-structured method, there is a confluence between the questions previously elaborated, based on the literature review, with others, that derive from the responses of the interviewees. The pre-defined questions served as guidelines but did not restrain the conduction of the interview. 
The researchers conducted a combination of open and closed questions, offering the interviewee the opportunity to freely discuss the subject.
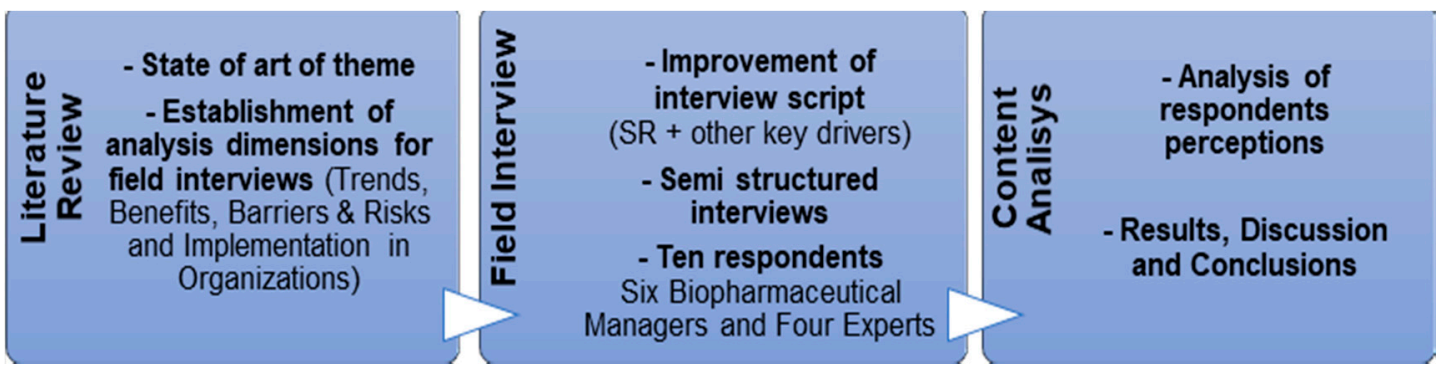

Figure 2. Methodological planning.

Table 1. Characteristics of interviewees—Biopharmaceutical Sector Managers and I4.0 Experts.

\begin{tabular}{|c|c|c|c|}
\hline Interviewed & Company Characteristics & Company Position & Interviewed Category \\
\hline $\mathrm{A}$ & $\begin{array}{l}\text { Portugal Private } \\
\text { Pharmaceutical }\end{array}$ & Industrial Director-Portugal & $\begin{array}{l}\text { Biopharmaceutical } \\
\text { Manager }\end{array}$ \\
\hline B & $\begin{array}{l}\text { Portugal Private } \\
\text { Pharmaceutical }\end{array}$ & $\begin{array}{l}\text { Digital Transformation Project } \\
\text { Manager-Portugal }\end{array}$ & $\begin{array}{l}\text { Biopharmaceutical } \\
\text { Manager }\end{array}$ \\
\hline $\mathrm{C}$ & $\begin{array}{c}\text { Transnational Private } \\
\text { Bioharmaceutical }\end{array}$ & $\begin{array}{l}\text { Academic Management Program } \\
\text { Manager-Spain }\end{array}$ & $\begin{array}{l}\text { Biopharmaceutical } \\
\text { Manager }\end{array}$ \\
\hline $\mathrm{D}$ & $\begin{array}{l}\text { Brazilian Private } \\
\text { Bioharmaceutical }\end{array}$ & Production Director-Brazil & $\begin{array}{l}\text { Biopharmaceutical } \\
\text { Manager }\end{array}$ \\
\hline $\mathrm{E}$ & $\begin{array}{l}\text { Transnational Private } \\
\text { Bioharmaceutical }\end{array}$ & IT Manager-Brazil & $\begin{array}{l}\text { Biopharmaceutical } \\
\text { Manager }\end{array}$ \\
\hline F & $\begin{array}{l}\text { Digital Transformation in } \\
\text { Production Lines }\end{array}$ & Digital Latin America-Brazil & $\begin{array}{l}\text { Biopharmaceutical } \\
\text { Manager }\end{array}$ \\
\hline G & $\begin{array}{l}\text { Artificial Intelligence (AI) } \\
\text { Consulting and I4.0 }\end{array}$ & $\begin{array}{l}\text { Head of Machine Learning and } \\
\text { Innovation R\&D_EUA }\end{array}$ & I4.0 Specilist \\
\hline $\mathrm{H}$ & $\begin{array}{l}\text { Digital Transformation in } \\
\text { Production Lines }\end{array}$ & Director (CEO)—Portugal & I4.0 Specilist \\
\hline I & $\begin{array}{l}\text { Academy University } \\
\text { of Coimbra }\end{array}$ & $\begin{array}{l}\text { Full Professor of } \\
\text { Robotics-Portugal }\end{array}$ & I4.0 Specilist \\
\hline $\mathrm{J}$ & $\begin{array}{l}\text { Private Microconductor } \\
\text { Company I4.0-Portugal }\end{array}$ & $\begin{array}{l}\text { Company Owner and } \\
\text { Director-Portugal }\end{array}$ & I4.0 Specilist \\
\hline
\end{tabular}

The interviews were recorded on audio upon the authorization from the interviewees, and exhaustively transcribed afterwards. The transcribed interviews were read with the purpose of identifying relevant points directly related with the research objective. The data from the interviews were analyzed according to prevalent content and narrative methods and guidelines, leading to the description, analysis, and interpretation of the data. Whenever possible, the interpreted information was presented in graphs to facilitate the readers' visualization and analysis.

Theoretical background material derived from the literature review phase allowed for a preliminary understanding of the topic and provided the basis for structuring field interviews. The results obtained and their discussion are presented in the following section. 


\section{Results and Discussion}

\subsection{General Perspectives and Trends}

The study documents a paucity of literature in the specific domain of I4.0 in biopharma expressed by the low number of documents identified during the literature review in the traditionally established scientific databases. The literature on I4.0 is growing, but still with a remarkable focus in some recurrent sectors including the automotive and aerospace industries, but it is still little explored in the biopharmaceutical field. Most of the documents on I4.0 in this area are still available only in specialized magazines in the sector. Figure 3 illustrates the number of articles identified across the years (with the majority published in the last 5 years). As noted earlier, these works served as conceptual ground for the developing interviews and conducing the corresponding content analysis.

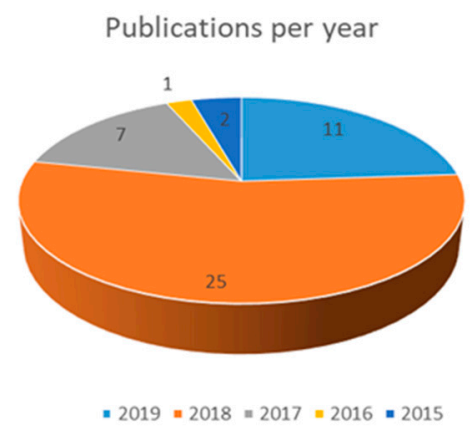

Figure 3. Year of publications included in this study (own elaboration).

An overarching argument that was advanced by most respondents addressed in the interview phase is the conviction about the need for biopharmaceutical companies to catch up with I4.0 knowledge and practices, suggesting the urge to foster the adoption of new technologies and the implementation changes in their operations and processes. The respondents were particularly aware of the strategic importance of I4.0 investments for the competitiveness of the industry. Some respondents highlighted that they expected that the adoption of I4.0 in the biopharma sector will occur at a slow pace, given the specific characteristics and peculiarities of the biopharma industry, notably the severe regulatory requirements that limit the operations in the sector, and the potential implications and risks for individual's health and safety associated with its products. The interviewee F, for example, expressed that the use of I4.0 elements is a matter of "survival", although recognizing that there is a strong need to break paradigms for the biopharmaceutical industry to embark definitively in the I4.0 era.

In general, the field interviews confirmed the main benefits and barriers described in the documents collected in the literature and brought some new points considered to be more peculiar to I4.0 in the production of biomedicines (see Table 2).

According to the perception of specialist $\mathrm{H}$, the need for I4.0 elements is directly related to the complexity of the final products. As such, for undifferentiated and non-customized products, of the applicability of I4.0 is perceived as lower. According to this perspective, consumer requirements link to solutions that are more adaptable, customizable, and adjustable to their specific needs. By focusing on biomedical areas, the interviewee envisions a huge evolution if certain drugs that can be produced to meet the specific characteristics of small groups of patients. In his view, industries that can present solutions to specific problems in a short time will completely dominate the market. He adds that some investments currently are only suitable for common medicines, but not for conditions that affect a smaller and more specific group of people. 
Table 2. Main benefits, barriers, and risks associated with I4.0, derived from the literature and added from insights collected in the field study (in the table with the + sign).

\begin{tabular}{ll}
\hline \multicolumn{1}{c}{ Main Benefits } & \multicolumn{1}{c}{ Major Barriers and Risks } \\
\hline Operating Cost Reduction & High Investment Level \\
Productivity increase & Organizational resistance (culture) \\
Better meeting deadlines & Absence of qualified professionals \\
Flexibility/Customization of lines and products & Threat to Information Security \\
More agile and decentralized decision making & Equipment and technology integration \\
Quality Improvement & Low IT Structure \\
Waste Reduction & Managers engaged in the theme I4.0 \\
New Product Launch & Absence of cases reported in the literature \\
Value Added and New Business Models & High degree of regulatory requirements \\
Sustainability/Social and Environmental & Unemployment-Social Bubble \\
Less bureaucratization-registration of activities & Lack of Strategies and Maturity for Implementation \\
Productive data integrity and traceability & Absence of government support \\
Safety of Biological Processes $(+)$ & Complexity of biopharmaceutical processes $(+)$ \\
Attenuates Ergonomic Risks $(+)$ & High Risks-Medical Area $(+)$ \\
\hline
\end{tabular}

In the view of manager B, for biopharmaceutical companies focused on transformation or final processing of Active Pharmaceutical Inputs (IFA) purchased externally, there is a real need to implement leaner, and more modern and cost-effective processes. According to him, in those companies where the commercialization margins are increasingly reduced due to the high prices of IFAs, the investment in the digitization and modernization of the production processes is an alternative to widen the profit margins a little more.

Some interviewees, despite their beliefs in the trend for implementing I4.0 in the biopharmaceutical industry, mention a slower pace of transformation due to the characteristics and peculiarities of the sector, including the strict regulatory requirements, the necessary caution for the manufacture of products that directly impact in people's lives. On the other hand, interviewee D, for example, highlighted that the regulatory bodies in the area already see I4.0 as a guarantee of greater reliability, integrity, and data traceability. On another interesting point of view, managers B and E believe that the difficulty and high prices for the validation of technologies inserted in the sector's production processes may be another moderating factor. According to them, there are cases in which the validation processes can cost two to three times more the value of the technology itself. Specialist I also believes in a moderate trend, since not all countries have the investment capacity, strategic objectives and specificities, for example, observed in Germany (which initiated the I4.0 movement).

\subsection{Benefits Associated with I4.0}

There was a strong alignment with the reported literature concerning the existence of benefits associated with the implementation of I4.0. The respondents in general expressed a belief the possibility of achieving gains and assisting biopharmaceutical companies in establishing more robust, flexible and more agile manufacturing processes. The various benefits highlighted by the interviewees were classified into four categories: Performance and Productivity, Competitiveness, Culture and Organizational Strategy and Regulatory Aspects and Socioenvironmental Responsibility, as illustrated in Figure 4.

The benefits related to the "Performance and Productivity" dimension were the most frequently cited by both categories of respondents (Area Managers and Experts). This dimension concerns the gains related to the improvement of production processes in biopharmaceutical organizations. Most noteworthy are aspects related to the improvement in operational efficiency, increased productivity, reducing bureaucracy (replacing paper records with digitized ones) and the setup of flexible production lines. 


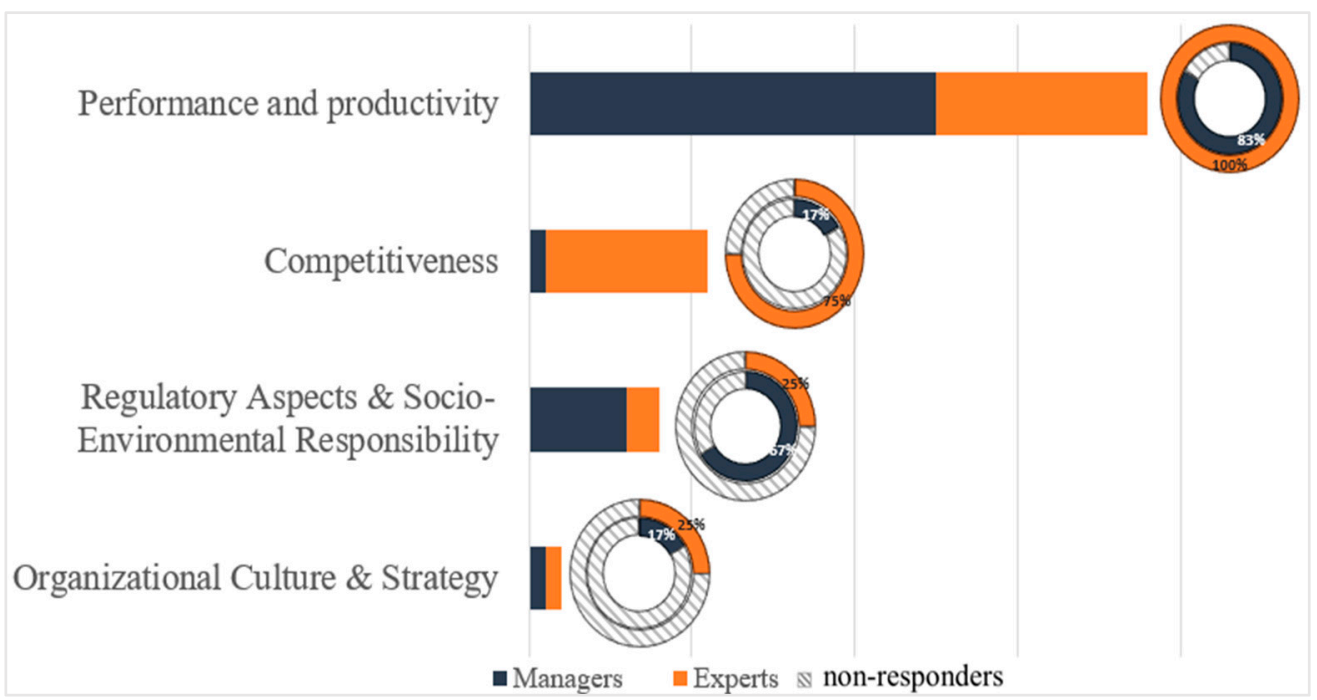

Figure 4. Perception of respondents (Managers and Experts) about the benefits to be achieved with I4.0 in the biopharmaceutical sector-Bar graph: quantity $\left(\mathrm{n}^{\circ}\right)$ of citations; pie chart: \% of the total respondents in each category they mentioned benefits (Own elaboration).

"Competitiveness" refers to benefits related to the market, addressing aspects that stimulate a company's differentiation towards other biopharmaceutical organizations. Most of the declarations collected from the respondents on this regard refer to the competitive relationship towards other companies (usually in the same business sector). The benefits (subdimensions) included in this dimension, particularly highlighted by the Experts in I4.0, suggest that this group has a stronger market focus. The respondents identified several factors enabled by I4.0 that would allow for competitiveness gains, including aspects related to the greater possibility of personalization and customization of products, reduced time for the launch of new products, reduction of prices practiced in the market, and more agile service to delivery times.

Regarding the dimension labelled as "Regulatory Aspects and Social and Environmental Responsibilities", the interviewees-mainly the Area Managers-believe in a better possibility of meeting them with the implementation of I4.0. They see considerable gains emerging in the quality of processes and products (a critical point in the biopharmaceutical sector), a greater possibility of storing data in a traceable, complete, and reliable way, in addition to procedures that value sustainability.

The dimension of "Culture and organizational strategy" aggregates the testimonials related with benefits in to organizational, governance and administrative aspects. In this domain, the interviewees cited the possibility of considerable optimization of the companies' resources and the opportunity for a positive change in the organizational culture so that the implementation of the elements and concepts of I4.0 is carried out successfully.

Table 3 shows in detail a distribution of the benefits collected in the interviews. There was a substantial match between the views expressed in the study and the benefits of I4.0 described in the literature. This study allowed also for the identification of specific areas of benefit that are very specific for the biopharma industry. Moreover, the analysis of the interviews' data supported the identification of the four dimensions discussed above.

Some concepts and elements recommended by I4.0 provide a basis for these expectations to be consolidated. Among the most relevant promises relevant for the biopharma industry are improvements in quality control enabled by with real-time data collection and analysis, predictive maintenance of equipment, machine to machine interaction, and the use of aseptic robots in production processes. The perspectives are that the management of quality of products and processes will be more rigorous and supported by analysis and productive lots anchored in powerful algorithmic models that allow for more agile and decentralized decision making [12]. These procedures could, for example, allow for 
important corrective actions during the production of a batch, or even recommend discarding it without the need to reach the end of the production process, therefore reducing the waste of unnecessary working hours, energy consumption, raw materials, among others [13]. As a result, strong gains in efficiency, productivity, and reduction of waste and operating costs are expected.

Table 3. Benefits scored by category of respondents considering the established dimensions—number of references.

\begin{tabular}{|c|c|c|c|}
\hline Dimensions & Benefits & $\begin{array}{c}\text { Area } \\
\text { Managers }\end{array}$ & $\begin{array}{c}\text { I4.0 } \\
\text { Specialists }\end{array}$ \\
\hline \multirow{3}{*}{$\begin{array}{l}\text { Regulatory Aspects and } \\
\text { Socio-Environmental } \\
\text { Responsibility }\end{array}$} & Reliability/Integrity/Data Traceability & 1 & 0 \\
\hline & Quality & 3 & 2 \\
\hline & Sustainability and socio-environmental responsibility & 2 & 0 \\
\hline \multirow{7}{*}{ Competitiveness } & Compliance with deadlines & 0 & 1 \\
\hline & Competitiveness & 0 & 1 \\
\hline & Greater availability of products on the market & 0 & 1 \\
\hline & New models & 1 & 1 \\
\hline & Customization & 0 & 2 \\
\hline & Market cost reduction & 0 & 1 \\
\hline & Reduction of time to market & 0 & 3 \\
\hline \multirow{2}{*}{$\begin{array}{l}\text { Organizational Culture } \\
\text { and Strategy }\end{array}$} & Organizational Culture Change & 0 & 1 \\
\hline & Optimization of Organization Resources' & 1 & 0 \\
\hline \multirow{10}{*}{$\begin{array}{l}\text { Performance and } \\
\text { productivity }\end{array}$} & Increased Productive Capacity & 2 & 0 \\
\hline & Automation-Economy with human resources & 0 & 1 \\
\hline & Reduction of bureaucracy & 2 & 0 \\
\hline & Reduction of errors linked to the human condition & 1 & 0 \\
\hline & Efficiency & 14 & 4 \\
\hline & Flexibility & 0 & 2 \\
\hline & Decrease of ergonomic risks & 0 & 2 \\
\hline & Improvement opportunities & 1 & 0 \\
\hline & Productivity & 3 & 4 \\
\hline & Process Security & 2 & 0 \\
\hline
\end{tabular}

\subsection{Elements of I4.0 and the Benefits in the Biopharmaceutical Sector}

This subitem summarizes the main technological elements (Figure 5) that make up the theoretical framework of I4.0 [3], considering both the literature review and the insights from the field interviews. Among the most important technological elements available in the era of I4.0 to consolidate these perspectives we have: CPS (mechatronic systems composed of sensors and actuators, and controlled by software) and IoT (allows objects, sensors, or equipment to be detected or controlled remotely through the network infrastructure). Both are considered fundamental elements. IoS (Internet of Services) is also seen as fundamental, but as it is focused on services, it was not prioritized in this study (which prioritizes the processes of production of biomedicines). 


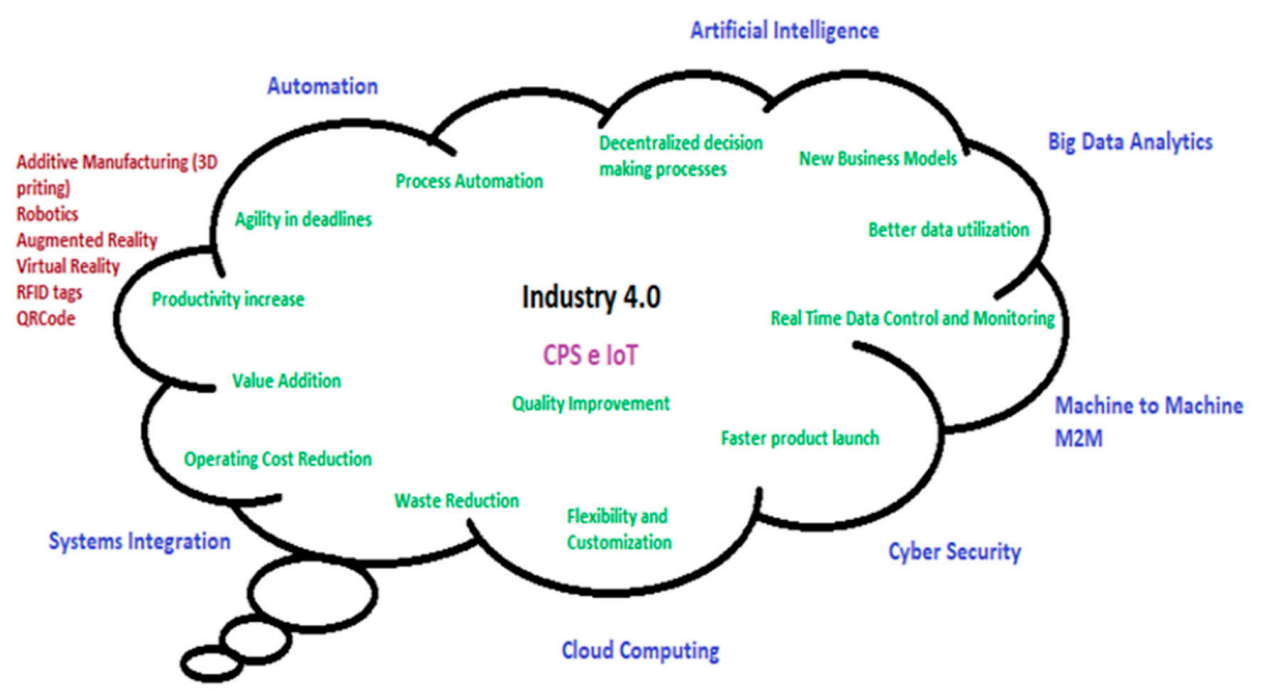

Figure 5. The main technological elements of I4.0.

As structuring elements for the implementation of I4.0, it is possible to list:

- $\quad$ Big Data (enables the collection and storage of large amounts of data at high speed);

- Artificial Intelligence (offering complex models for predictions and decision making based on advanced algorithmic analyzes based on data from control available during the process or in Big Data);

- Cloud Computing (essential for information and data to be accessed from anywhere in the world and enabling decentralized decision making);

- Machine-to-Machine (M2M): communication between machines linked to factory automation systems through the IoT independently and that can act without the need for human intervention;

- Automation: the enabling of technological elements to connect and work autonomously;

- System Integration mentioned as fundamental for the operation of equipment and systems during manufacturing processes and Safety Cybernetics;

Other complementary elements include:

- Robotics: identified as important for the biopharmaceutical field for their potential to reduce the exposure of operators to repetitive processes and ergonomic, chemical, or biological risks;

- 3D printing that can work as a complementary alternative for the production customized biomedicines;

- Virtual Reality offering users the possibility to see and learn about biopharmaceutical processes before they are conceived in the real world;

- Augmented Reality: referred as important to allow for the visualization of the positioning of components in biotechnological system assemblies;

- RFID tags or QR Code: as identifiers that can send information and commands to process equipment;

In what concerns the views from interviewees about these I4.0 elements, manager A expressed the belief that the control of processes in real time is one of the focal points for the biopharmaceutical sector. For the specific issue of waste reduction, manager B believes that the replacement of people (at specific points in the production system) by predefined systems or automatic decisions will not only significantly reduce errors or failed batches, but also the considerable time spent to justify these deviations in face of regulatory authorities. Specialist H, on the other hand, believes that the main benefits of intelligent processes come from the ability to solve problems without stopping the operation and, in many cases, without the need for human intervention. 
Some documents collected in the literature describe the pharmaceutical industry as still being based on productive control at the end of each batch. The literature reinforces that advanced process control solutions (APC) based on tools included in Process Analytical Technology (PAT) integrate several analytical technologies, which, through calculations based on complex algorithms, allow for predictive analysis and actions during a productive lot aiming to avoid or correct process or equipment failures [14]. In a fermentation or cell propagation process for the production of an IFA, for example, increased levels of control and real time monitoring for parameters of a reaction environment containing living cells (e.g., $\mathrm{pH}$, temperature, dissolved oxygen, among others) allow for a stronger probability of detection of any possible deviation. This would increase the chances of obtaining the desired products or even avoiding waste.

In the biopharmaceutical sector, this is a fundamental perspective due to the complexity of biotechnological processes (an aspect that was mentioned by some of the interviewees as a barrier). Generally, products obtained through systems composed of living cells (prokaryotic or eukaryotic) are unstable and unpredictable, especially if not controlled and rigorously monitored [8]. Back in 2006 Pisano [15] has already told about the difficulty of technological innovation due to uncertainty among the characteristics of biotechnology. Still today, this is a distress and it is very important that the same reproducibility appears at the stage of production.

Manager E believes that the great potential of I4.0 for the biopharmaceutical sector lies in the fact that it does not have to wait for the collection of samples and for the quality release at the end of the production process. Interviewee G, a specialist in solutions offered by I4.0, adds that the most advanced algorithms today concern data analysis and for allowing for reproducibility and permanent control (instead of sampling control).

Another point raised by the interviewees, especially by biopharmaceutical managers, is the possibility of predicting wear, damage, and equipment malfunction through algorithmic analysis of the thousands of data generated by them or by the production processes themselves. In this sector, the equipment is often located in aseptic areas and is frequently subject to the action of highly aggressive cleaning agents. Therefore, many of them have frequent episodes of breakdown, wear, or malfunction. The sooner these problems are detected, the greater the possibility that actions will be taken to correct flaws or deviations. Thus, with predictive maintenance based on the actual conditions of the equipment, the prospects are for a considerable reduction in unplanned interruptions, less episodes of defects with production line equipment, and better meeting deadlines. Interviewee B adds the importance of mapping all events that may occur in the equipment during the production processes so that, in the event of unexpected events, the machines themselves (or even the technicians) can intervene or adjust accordingly.

Intelligent processes are expected to be increasingly useful in the biopharmaceutical field. A temperature or $\mathrm{pH}$ sensor positioned at a specific point in a biological process, for example, can not only transmit the collected values to a computer or a cell phone, but also compare them to the programmed standard values and, if necessary, send signals to the actuators to correct the temperature or $\mathrm{pH}$ without any human intervention [3]. The possibility of using intelligent aseptic robots can also be interesting in excessively repetitive processes or in those involving physical, chemical, or biological risks [16]. Interviewee I reinforces that there are specific activities where people are able to work attentively up to a certain time. After that, attention span inevitably starts to degrade. This is not the case with machines that can work uninterruptedly. On the other hand, the same respondent points out that success in the use of technological tools and automated processes will necessarily involve human intervention, at least in the first instance. In his perception, the ability to interconnect technologies will result from study, experiments, time for reflection, planning, understanding the scenario and the possibility of integrating all this through human hands.

The perspective of machines interacting directly with other machines in closed systems without the need for human intervention is a very interesting point in the production of biomedicines. Some respondents pointed out the expectation of gains in quality and efficiency related to the reduction 
of failures linked to the human condition. Manager B showed great concern about deviations caused by human intervention (due to contamination, repetitive tasks, among others). The literature points out that area operators are important sources of external contamination in processes that require sterility or maximum asepsis. The simple entry of a particle from the breath into a batch of vaccine or biopharmaceutical, for example, can make whole batches unfeasible and generate millionaire losses [8]. Another advantage in production in machines or closed systems, would be the reduction of the need for high investments in the construction and maintenance of clean rooms, since the machines could communicate and act without contact with the external environment.

The gradual replacement of manual data entry with digitized records is another point addressed by I4.0. Sustainability gains and data traceability were frequently mentioned in the interviews, especially by managers working in the biopharmaceutical sector. Interviewee $C$ reinforces that environmental responsibility is increasingly present in companies. In addition to saving paper, electronic records allow for better meeting regulatory agencies longing for reliability, as they hamper malicious data handling [11]. As the biopharmaceutical industry is highly regulated, the amount of paper generated in the process documentation is quite large. Managers A and B believe that digitalization also generates a significant reduction of bureaucracy in the processes with significant savings in work and availability of physical space. The possibility of storing, and consequently tracking, process data for several years is of supreme importance for investigating deviations or studying better process conditions. The specialist I adds that the transparency of the digitized data collected is of great value for the entire logistics chain of the organization, ranging from the acquisition of raw materials to obtaining the finished product.

The ability to analyze in depth any amount of data generated and stored is also an important perspective for the production processes. The direct connection between IoT, Big Data, AI, and cloud computing will allow for a more accurate data crossing and the establishment of more reliable indicators that provide information that effectively assist a faster and decentralized decision-making process, according to the best available practices [17]. For assessment and decisions about, for example, potential environmental impacts caused by a biochemical process, the manager may have access to information collected from various sources, such as environmental impact banks, history of regulatory compliance, among others. Thus, managers will be able to make decisions based on the largest amount of data and information possible. Manager F, by stating that "doing more with what already exists", believes that among the main benefits expected by I4.0 is the possibility of managing processes more efficiently and consequently optimizing the use of material, tooling, and human resources.

The field interviews also supported the arguments in the literature related to I4.0 with leaner, more flexible production lines that allow the manufacture of products increasingly customized or personalized. This is an interesting perspective for the biopharmaceutical sector, since it is common for a certain type of biomedical (a therapeutic protein, for example) to serve a small and targeted niche of patients. Through the automation of the production processes proposed by I4.0, the expectation is that the manufacturing will become leaner and with more cost-effective operations. Thus, as also reinforced by specialist I, it would be financially viable for compensate organizations to produce certain biomedicines even on smaller scales, offering these products at affordable costs to the target niche.

The literature describes that the establishment of intelligent factories designed with flexible modular structures can significantly assist in the manufacture of different products with the option of greater customization [18]. On this point, specialist $\mathrm{H}$ believes that as new market situations or new demands arise, the speed and capacity required for manufacturing facilities will be strongly influenced by the flexibility they have and will differentiate them in competitive terms. The specialist I reinforces this point by saying that the agility in meeting deadlines and demands is directly related to the flexibility of the production lines. Still on this aspect, the literature points out that the high costs embedded in most of the biopharmaceutical sector's manufacturing operations are generally associated with facilities operating below full capacity. The more flexible, lean, and customizable the production lines of the smart factory are, the greater the likelihood of reducing idle capacity and 
increasing occupancy with new products. On the other hand, it is challenging to design modules or flexible factories that meet the strict regulatory requirements of the biopharmaceutical sector [8].

Another trend in the biopharmaceutical industry is the growing use of systems called single use. There are relatively simple systems of this type, but others are extremely complex. The assembly of a disposable bioreactor (single use), for example, may require significant manual efforts to connect all the parts necessary for the process. Intelligent graphics and augmented reality can assist operators in positioning and recognizing parts when placed in the correct locations. An intelligent system can avoid wasting time and resources when it is configured to require the operator to register, for example, the barcode of each disposable part positioned and thus ensure the proper assembly and traceability of the components [12].

The tools of virtual or augmented reality can offer substantial support here, avoiding errors, reducing waste and increasing the safety of the process. By using augmented reality glasses, for example, the operator can see where each part of a system should fit. Another point cited especially by the experts is about the expectation that more products (in the case of biomedicines) will be available to consumers more quickly. Among other elements of I4.0 that will contribute to this end, modern virtual simulators quickly manufacture and evaluate products under development, without the need for physical occupation of factories and promoting a faster arrival of new biopharmaceutical products to the markets. Specialist $\mathrm{G}$ adds that the possibility of directly correlating a large amount of data obtained from an unprecedented molecule with its interactions and pharmacological effects can save time, experiments and human resources. He believes that, on the one hand, there will be some job losses, on the other hand, there will be a greater availability of products on the market with a lower cost to the consumer.

\subsection{Barriers and Risks Associated with I4.0}

The study also addressed the barriers and risks associated with the implementation of I4.0. On this regards, the interviewees' opinions were also quite diversified. The data analysis allowed for its aggregation into five major dimensions as follows: Endogenous Characteristics (i.e., inherent to the production of biomedicines), Management and Organizational Strategy, Human Resources and Infrastructure, Investment and Return and Social Impact (displayed in Figure 6).

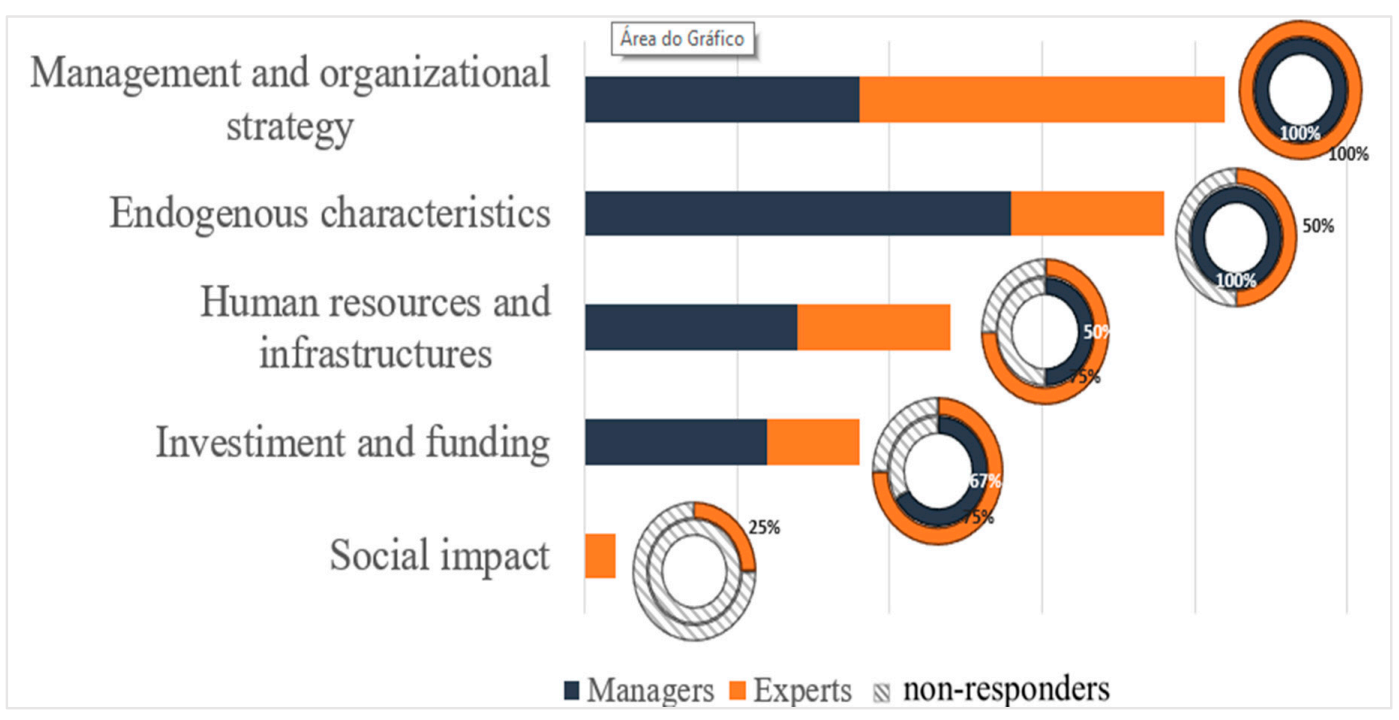

Figure 6. Perception of respondents (Managers and Experts) about the barriers to implementing I4.0 in the biopharmaceutical sector-Bar graph: quantity (number) of references; pie chart: \% by category of total respondents who mentioned barriers. 
The analysis of Figure 6 shows that all interviewees identified as significant barriers the need to change the organizational culture of companies and the development of a structured strategy to carry out the digital transformation and implantation of the elements technological developments in biopharmaceutical organizations. Some interviewees reinforced that this is a fundamental condition for the success of any digital transformation project.

Another point to be highlighted is the concern, mainly of the managers who work in the biopharma, with the inherent and specific characteristics of the biopharmaceutical sector. These characteristics include complexity of biological processes, the strict regulatory requirements to be met in the area and the absence of robust scientific studies on the application of I4.0 concepts and elements in this industry. In the perceptions of some of the interviewees, discussed in detail ahead, these specificities of the biopharmaceutical industry may limit the pace of implementation of I4.0 in the sector.

Some interviewees also pointed out the difficulties of attracting qualified human resources, trained and prepared to work with certain technological elements recommended by I4.0, especially when applied to the biopharmaceutical industry. According to them, there is a significant deficit in relation to the training of professionals who work in certain areas related to digital transformation. Another critical point is often the lack of infrastructure in organizations or the environment in which they operate to receive or integrate the technological elements of I4.0.

The aspects related to the high investment required and the uncertainty of return were also scored. However, some interviewees pointed out that many projects and initiatives have a significant financial contribution but are unsuccessful because they ignore issues related to the absence of strategies for implementing I4.0 and organizational cultures in a cast. Another point to be noted is that only one of the interviewees (a I4.0 expert) explicitly mentioned the concern about the risk of the so-called "social bubble" to be caused by unemployed professionals due to the greater automation of processes and the change in the skills and competences to be demanded. The question was also addressed by other interviewees, but they see that there will be a natural repositioning with the absorption of professionals with new profiles and skills.

Table 4 details the barriers and risks collected in the interviews that were organized into to the dimensions discussed above. The points generally coincide with what is reported in the literature and are discussed in detail below.

A point of strong consensus across both the interviewees and the literature is the difficulty of identifying qualified, multidisciplinary and trained professionals to work in the sector, who have significant knowledge of the technological elements recommended by I4.0. It was pointed out that universities are not yet ready to meet this demand. The professions as known in current days are likely to be replaced or updated to support this new technological revolution. The professionals of the future will probably need to have an increasingly multifunctional profile. Some articles describe that this interdisciplinary combination is extremely critical and challenging for the biopharmaceutical sector [14]. In the manager's view, it becomes even more delicate due to the difficulty in the interconnection between companies and universities in most countries. The problem is framed by most of the recently graduated professionals having theoretical knowledge but lack experience in practical reality.

Interviewee E, manager in the Technological Information area for a large biopharmaceutical company, acknowledges the extreme difficulty in finding professionals specialized in the market, for example, in Data Science, Artificial Intelligence and IoT. In the opinion of F and I, the issue of human resources is extremely serious, since many of the necessary professionals do not yet exist in the market. Some articles describe the importance of having more qualified and prepared professionals to work in the I4.0 era. In one of them, the authors assess in the Czech Republic the need for better training of workers for I4.0 through the modernization of the education received in the country's colleges and universities [4]. 
Table 4. Barriers and Risks punctuated by category of respondents considering the established dimensions.

\begin{tabular}{|c|c|c|c|}
\hline Dimensions & Barriers and Risks & $\begin{array}{c}\text { Area } \\
\text { Managers }\end{array}$ & $\begin{array}{c}\text { I4.0 } \\
\text { Specialists }\end{array}$ \\
\hline \multirow{5}{*}{ Endogenous characteristics } & Lack of scientific materials/cases & 4 & 0 \\
\hline & Characteristics of the biopharmaceutical sector & 1 & 0 \\
\hline & Complexity of biological processes & 0 & 2 \\
\hline & Regulatory requirements and barriers & 8 & 2 \\
\hline & High Risks-Medical area (Security) & 1 & 1 \\
\hline \multirow{4}{*}{$\begin{array}{l}\text { Human Resources and } \\
\text { infrastructures }\end{array}$} & Lack of trained/qualified human resources & 3 & 4 \\
\hline & Obsolete/deficient infrastructure & 1 & 0 \\
\hline & Systems and Equipment Integration & 1 & 1 \\
\hline & Information security & 2 & 0 \\
\hline \multirow{3}{*}{ Investment and funding } & High Investment & 3 & 2 \\
\hline & Government Support & 0 & 1 \\
\hline & Difficulty in quantifying financial return & 3 & 0 \\
\hline \multirow{6}{*}{$\begin{array}{l}\text { Management and } \\
\text { Organizational Strategy }\end{array}$} & Organizational culture-managing change & 5 & 2 \\
\hline & Dissemination of I4.0 culture in society/value chain & 1 & 1 \\
\hline & Lack of organizational strategy/Planning & 1 & 5 \\
\hline & Lack of business maturity & 0 & 1 \\
\hline & Lack of conceptual standardization & 1 & 2 \\
\hline & Time required for implantation/experiments & 1 & 1 \\
\hline Social impact & Unemployment-Social bubble & 0 & 1 \\
\hline
\end{tabular}

Specialist I cited a 2018 study that advanced a deficit in Europe of approximately 1 million professionals in the field of data science alone. In his perception, besides the inability of the European universities covering this demand, human resources are still being trained under another, outdated, paradigm. Thus, there is an imposing a transformation or revolution mismatched with the human resources capacity to supply the demand. In addition, the nature of the activities recommended by I4.0 provides a gradual replacement of human work by machines or robots. In his view, these facts can result in serious consequences in relation to the repositioning of unemployed professionals (a kind of "reaction to technology").

Issues related to the difficulty of changing organizational culture and the lack of coordinated strategies for implementing the technological elements of I4.0 in line with the positioning and objectives of organizations were aspects strongly pointed out by the interviewees, as well as verified in the literature. In the perception of A, the speed of transition of organizations towards the era of I4.0 will be dictated by the ability to change, and to adapt to new environments, to incorporate new concepts and to obtain specific information in the market. There is still a lack of organizational confidence caused mainly due to the extremely conservative and highly regulated characteristics of the biopharmaceutical industry.

In the view of manager $\mathrm{B}$, the implantation of the elements and concepts of I4.0 will require a cultural change of organizations without an absolute certainty of return. Interviewees C, E, and J describe that the implementation of I4.0 requires a change in mentality. According to them, an adaptation period is necessary and a change with a structured management plan will be essential for this. Companies need to prepare in advance, since people generally think it is better to "do it the way they have done it for years". In the view of specialist J, it is important that top managers be able to "stir people's panache" 
and make them understand that they are a fundamental part of the change process. By sharing his personal experience, as owner of a factory, he concludes that, after the completion of the digitization project, people reported the usefulness of the knowledge obtained as being more valuable than a university course.

Still on the changing aspect of organizational culture, in the perception of $C$ it is interesting to use familiar terminologies to facilitate understanding and establish indicators to measure the success to be obtained. Although the difficulty of measuring return is also one of the barriers listed during the interviews, specialist $\mathrm{H}$ believes that there are concrete steps with tangible results to estimate the effectiveness of the implementation. It is possible to identify if the processes are having less human influence, if the costs were reduced, if the times of introduction (or manufacture) of new (or old) products were changed, if it was possible to implement incremental improvements based on the best use of the obtained data, among others. Specialist I adds that it is interesting for managers to make themselves available to visit other companies in advance and check how it works (benchmarking is important). In his view, it is essential that managers sponsor the movement before engaging shop floor operators. Another interesting perception, from interviewees $\mathrm{F}$ and $\mathrm{H}$, is the belief that breaking cultural resistance depends on the end of the "niches" that exist in companies.

Another point that is strongly cited is the absence of clear definitions, based on strategy, positioning, and organizational objectives, for the insertion of the technological elements recommended by I4.0. According to interviewees $\mathrm{E}$ and $\mathrm{H}$, a detailed prior assessment of what is relevant to the company, what makes sense to deploy, where the organization is located and where it intends to reach should be carried out. Without this prior analysis, there is a risk that the technologies deployed will not generate expected returns. In H's view, the great problem of I4.0 lies in companies investing in a practically random manner and, as a result, the elements are not able to be integrated or rather end up with little or no applicability. He pointed out that it is no use for a given company to hire an I4.0 director to do a digital transformation process if it is not aligned with the organization's strategies and objectives.

Still on the importance of a pre-defined strategy, expert $\mathrm{G}$ believes that most implementations may not work because it ends up emphasizing the delimitation of the technology and not the objectives of the companies. The technological elements in the perception of $G$ are just tools. Most of the failures or delays in their application occur because companies prioritize, anticipate or over-value some to the detriment of others. The interviewee added that most companies lack strategic, business, or technological maturity to choose and implement the necessary technological elements. According to $\mathrm{G}$, it is important to form a multidisciplinary team in the company to conduct the implementation strategy with the involvement of executives (who defines the importance and what can be done), specialists in specific areas and technicians specialized in the installation of the selected technological elements. The interviewee complements by stating that the formulation of the problem is often more important than the definition of how to solve it. Finally, he brought the example of a company that tried to produce cars without human intervention and was unsuccessful because certain tasks became too complex to automate. The variation rates started to increase significantly and the percentage of error ended up not compensating the manufacturing. The interruption of the production lines started to occur very frequently and it was necessary to hire people for certain functions in which the technologies were not sufficient to guarantee the success of the production.

For $\mathrm{H}$, the challenge of I4.0 is not to digitize or automate everything, but to find an efficient model that allows to combine the digitization and artificial intelligence work provided by the systems with the available human labor. Specialist J, a partner-director of a medium-sized micro-conductor company designed under the concepts of I4.0, reiterates the importance of planning that follows clearly defined objectives and strategies. He reported that in his company it was essential to seek intense communication and integration between the different equipment suppliers. According to him, the total implementation took about four years, with the first two dedicated mainly to planning, market research, price negotiation, and discussion with potential customers. 
On the question of the necessary high cost, some interviewees such as manager D, emphasized that the need to modernize and update the industrial park-including the interface between equipment, systems and building automation-will inevitably imply a high investment grade (which can be a huge barrier for small-medium sized businesses). In addition, the downtime (critical in the biopharmaceutical industry) of the industrial park (often facing external pressure from customers as reported by specialist J) must be considered so that all implantation procedures are performed and validated. Interviewee $\mathrm{E}$ adds that validation processes can represent up to two thirds of the cost of a given technology in this area. Compared to other areas, specialist $G$ believes that investments in the production of biomedicines should be greater due to the need for a lower margin of errors (high regulatory requirements).

Other factors such as deficient or obsolete IT infrastructure, little dissemination of the I4.0 culture in society, lack of government incentives and difficulties in integrating the systems were also pointed out. Manager F believes that many industries are still at I3.0. This includes industrial parks with basic PLCs (Programmable Logic Controllers), lack of Wi-Fi network structure, operations still too segregated across the factory floor, obsolete machines, among others. He adds that in these cases there is a lot of work even before thinking about cloud computing, artificial intelligence, among others. Specialist J believes that the government helps when it adopts policies to support companies in the processes of digitization and modernization of their technology parks.

Regarding cultural dissemination, in the perception of interviewees $\mathrm{B}$ and $\mathrm{H}$, it is essential that the entire logistics chain (customers, suppliers, regulatory agencies, among others) are able to evolve into the era of I4.0. Specialist H emphasizes that I4.0 concepts need to be rooted throughout the value chain. The technological elements are underused when a given organization has its processes automated and digitized, but its suppliers are unable to keep up. Interviewee J cited the example of his company in which the participation of the main customer was fundamental in the implementation of the concepts and elements of I4.0. According to him, the client had extensive experience and made part of his time and human resources available for knowledge transfer.

The integration between the different systems, mentioned by some interviewees, is another extremely challenging point for I4.0. Many equipment or devices that operate with systems developed by their own manufacturers or suppliers may, in many cases, not integrate with equipment systems developed by other manufacturers, mainly due to the lack of standardization [12]. Several efforts are being made to standardize the "language" of the systems employed to reduce this type of problem.

The fragility of information security systems is also a cause for concern. Studies suggest the use of modern protocols to establish an adequate level of security. It is a good practice, for example, to separate business data from production information in GMP areas using a type of "industrial segregated zone" [12]. It is strongly challenging to keep security levels up-to-date due to the increasing amount of data collected resulting from increased connectivity between systems, equipment and processes that communicate through the IoT. The mobile connection with access to confidential process data services performed by cell phones or portable computers is also a problem to be considered. The managers $\mathrm{D}, \mathrm{E}$, and $\mathrm{F}$ reinforce this concern by pointing out that these new models of operations must guarantee not only the traceability of the data, but also the compliance with protection protocols related to the invaders. This fact makes the process slower and more costly.

Finally, some studies were useful in identifying a slower pace of insertion of I4.0 in the biopharmaceutical industry when compared to other areas, such as a semiconductor company in Silicon Valley and a fashion fabrics company [19]. As corroborated by the field interviews, this can be justified by some restrictive factors. In addition to the issues directly related to products (biomedicines) that can put people's lives at risk (mentioned by interviewees F and G), there is a high degree of regulatory requirements, uncertainty of return on the high investments required (reported by managers A, E, and B). Likewise, the high complexity of biotechnological processes (according to specialist G, the models are difficult to be interpreted and replicated because they contain hundreds of variables) and the absence of concrete cases in companies in the sector described in the literature. On this last 
point, managers A, C, D, and F reinforced the little exchange of scientific experience based on real cases and suggested the creation of forums for discussion in the sector.

\section{Conclusions}

In general, field interviews reinforce not only a trend, but the need for biopharmaceutical companies to enter the I4.0 Era, under the risk of losing competitiveness. The results collected in the field supported the main findings in the literature, while also adding other aspects, from the perspective of the biopharmaceutical industry.

Regarding the main benefits for the sector, there are gains related to Performance and Productivity-mostly related to the increase in operational efficiency and production capacity. The advantages related to Competitiveness, such as greater possibilities for personalization/customization, better meeting deadlines and reduced time to market were also significantly scored. The possibility of better complying with Regulatory Aspects and Social and Environmental Responsibilities was also mentioned by the interviewees.

Regarding the production of biomedicines, the technological elements recommended by I4.0 can enable significant changes. We highlight the possibility of rigorous real-time monitoring and consequent performance in complex and unstable production processes, remote/virtual monitoring of production (allowing decentralized decision-making), the reduction of human interventions due to greater automation, the digitization of records and automation of processes (minimizing contamination episodes, ergonomic risks, and errors inherent to the human condition), the prediction of the need for equipment maintenance, the simulation of production processes without physical occupation of industrial facilities and the flexibility of the lines for manufacturing quantities smaller and more targeted at small groups of patients.

In what concerns the main barriers and risks, special notice goes for the rigidity of the organizations' culture and the absence of previous strategies for the orderly implementation of the technological elements of I4.0. The difficulty in identifying qualified professionals to work in the I4.0 era and the need for high investment without the certainty of return were also frequently reported. The barriers and risks inherent to biopharmaceutical production processes, such as strict regulatory requirements, the high complexity of biological processes, and the risk of products that directly impact on human life were also significantly scored and probably contribute to a slower pace of implantation of I4.0 in the biopharmaceutical industry than in other sectors.

The absence of real reports about the implementation of I4.0 in companies in this sector in the literature was also pointed out in the interviews as a barrier and can present an interesting opportunity for new publications that even encourage organizations in the area to migrate to the I4.0 Era. It is essential to promote a profound exchange of knowledge and experience on the impacts of I4.0 on the biomedical sector between producers, suppliers, customers/patients, regulatory bodies, and society in general. Industry 4.0 brings a paradigm shift that is recognized by all interviewees. It requires adapted management and organizational strategies, enabling adequate responses to the accelerated innovation cycle.

Recent debates have highlighted that the generalization of I4.0 principles, will result in the fragmentation of value chains and for this reason lead to emergence of new business models [20]. Likewise, another important consequence associated with the implementation of I4.0 is the potential for increasing the transparency and the traceability of the whole production process and the product lifecycles. Such visibility will likely create business opportunities in order to address sustainability issues [21,22]. Changes and innovations will be steamed by the adoption and the advances in technologies such as $\mathrm{AI}$, and big data that increasingly enable the applications of technologies to new markets, redefining the roles of humans and technologies in production and consumption processes, and creating the scenario for disruptive innovation [23]. The expectations about the importance that disruptive innovations will have in the near future bring open innovation to the top of the corporate agendas. As the nature of the changes to address are to a great extent difficult to foresight, companies 
would benefit from a greater involvement in networks with other companies and entities engaged in research and innovation [6]. The technological dimension calls for an effective match with business models, based on collaborative networks, despite the market's competitive rules. Open innovation models offer an interesting framework to deal with these challenges [24].

Finally, this study had as main limitation the difficulty of attracting more participants, especially strategic managers who work in the biopharmaceutical production area. Although many attempts at contact were made, few managers were willing to participate in the study. This is an area where information is very restricted for reasons of confidentiality. As future perspectives, a broader study is planned, with the participation of a greater number of managers in the area studied and monitoring a real case of implementing I4.0 in a biopharmaceutical company.

Author Contributions: Conceptualization, F.S.; methodology, F.S. and M.B.; software, M.B.; validation, F.S., D.R., M.A. and M.B.; formal analysis, F.S., D.R., M.A. and M.B.; investigation, F.S.; resources, M.A.; data curation, F.S. and M.B.; writing — original draft preparation, F.S.; writing—review and editing F.S., D.R., M.A. and M.B.; visualization, F.S., D.R., M.A. and M.B.; supervision, D.R.; project administration, F.S., D.R. and M.A.; funding acquisition, M.A. All authors have read and agreed to the published version of the manuscript.

Funding: This research was financially supported by the research unit on Governance, Competitiveness and Public Policy (UID/CPO/04058/2019), funded by national funds through FCT-Fundacão para a Ciência e a Tecnologia.

Conflicts of Interest: The authors declare no conflict of interest.

\section{References}

1. Daudt, G.; Willcox, L. Reflexões críticas a partir das experiências dos Estados Unidos e da Alemanha em manufatura avançada. BNDES Setorial. 2016, 44, 5-46.

2. Great Myanmar Institute. Revoluções e o Mundo. 2016. Available online: http://www.greatmyanmarinstitute. com/revolution/ (accessed on 22 January 2020).

3. Sacomano, J.; Sátyro, W. Indústria 4.0: Conceitos e elementos formadores. In Indústria 4.0: Conceitos e Fundamentos; Edgard Blucher Ltd.: São Paulo, Brazil, 2018.

4. Vrchota, J.; Mařiková, M.; Řehoř, P.; Rolínek, L.; Toušek, R. Human Resources Readiness for Industry 4.0. J. Open Innov. Technol. Mark. Complex. 2020, 6, 3. [CrossRef]

5. Morrar, R.; Husam, A.; Saeed, M. The Fourth Industrial Revolution (Industry 4.0): A Social Innovation Perspective. Technol. Innov. Manag. Rev. 2017, 7, 12-20. [CrossRef]

6. Lee, M.; Yun, J.; Pyka, A.; Won, D.; Kodama, F.; Schiuma, G.; Zhao, X. How to Respond to the Fourth Industrial Revolution, or the Second Information Technology Revolution? Dynamic New Combinations between Technology, Market, and Society through Open Innovation. J. Open Innov. Technol. Mark. Complex. 2018, 4, 21. [CrossRef]

7. Rader, A.; Langer, S. Biopharma Manufacturing Markets. 2018. Available online: https://www. contractpharma.com/issues/2018-05-01/view_features/biopharma-manufacturing-markets/49796 (accessed on 12 July 2019).

8. Silva, F.; Caulliraux, H. A Desverticalização no Setor de Produção de Biomedicamentos e a Utilização das Empresas CMOs (Contract Manufacturing Organization). Produto Produção 2016, 17, 1-18. [CrossRef]

9. Petrillo, A.; De Felice, F.; Cioffi, R.; Zomparelli, F. Fourth industrial revolution: Current practices, challenges, and opportunities. Digit. Transform. Smart Manuf. 2018, 1-20. [CrossRef]

10. Horváth, D.; Szabó, R.Z. Driving forces and barriers of Industry 4.0: Do multinational and small and medium-sized companies have equal opportunities? Technol. Forecast. Soc. Chang. 2019, 146, 119-132. [CrossRef]

11. Stentoft, J.; Adsbøll Wickstrøm, K.; Philipsen, K.; Haug, A. Drivers and barriers for Industry 4.0 readiness and practice: Empirical evidence from small and medium-sized manufacturers. Prod. Plan. Control 2020, 1-18. [CrossRef]

12. Markarian, J. Industry 4.0 in Biopharmaceutical Manufacturing-Modern technologies offer opportunities to increase manufacturing efficiency. BioPharm Int. 2018, 31, 36-38. 
13. Gaertner, R. Pharma 4.0: Quality Management in the Digital Age. European Pharmaceutical Manufacturer. 2015. Available online: https:/www.epmmagazine.com/opinion/quality-management/ (accessed on 22 October 2019).

14. Romero-Torres, S.; Wolfram, K.; Armando, J.; Ahmed, S.; Ren, J.; Shi, C.; Guenard, R. Biopharmaceutical Process Model Evolution- Enabling Process Knowledge Continuum from an Advanced Process Control Perspective. American Pharmaceutical Review 2018. Available online: https: //www.americanpharmaceuticalreview.com/Featured-Articles/352447-Biopharmaceutical-Process-ModelEvolution-Enabling-Process-Knowledge-Continuum-from-an-Advanced-Process-Control-Perspective/ (accessed on 24 November 2019).

15. Pisano, G.P. Science Business: The Promise, the Reality, and the Future of Biotech; Harvard Business Schoool Press: Boston, MA, USA, 2006.

16. Keller, M.; Baum, G.; Schweizer, M.; Bürger, F.; Gommel, U.; Bauernhansl, T. Optimized Robot Systems for Future Aseptic Personalized Mass Production. Procedia CIRP 2018, 72, 303-309. [CrossRef]

17. Festa, G.; Safraou, I.; Cuomo, T.; Solima, L.; Journal, M. Big data for big pharma: Harmonizing business process management to enhance ambidexterity. Bus. Process. Manag. J. 2018, 24, 1110-1123. [CrossRef]

18. Hammer, C. Digitisation \& Industry 4.0 in Pharma Production. ONdrugDelivery Mag. 2018, 83, 81-83.

19. Bertola, P.; Teunissen, J. Fashion 4.0. Innovating fashion industry through digital transformation. Res. J. Text. Appar. 2018, 22, 352-369. [CrossRef]

20. Prause, G. Sustainable business models and structures for Industry 4.0. J. Secur. Sustain. Issues 2015, 5, 159-169. [CrossRef]

21. Luthra, S.; Kumar, A.; Zavadskas, E.K.; Mangla, S.K.; Garza-Reyes, J.A. Industry 4.0 as an enabler of sustainability diffusion in supply chain: An analysis of influential strength of drivers in an emerging economy. Int. J. Prod. Res. 2020, 58, 1505-1521. [CrossRef]

22. Stock, T.; Obenaus, M.; Kunz, S.; Kohl, H. Industry 4.0 as enabler for a sustainable development: A qualitative assessment of its ecological and social potential. Process. Saf. Environ. Prot. 2018, 118, 254-267. [CrossRef]

23. Yun, J.J.; Won, D.; Jeong, E.; Park, K.; Yang, J.; Park, J. The relationship between technology, business model, and market in autonomous car and intelligent robot industries. Technol. Forecast. Soc. Chang. 2016, 103, 142-155. [CrossRef]

24. Kohnová, L. Overcoming Industry 4.0. Challenges through Open Innovation: Literature Review. Bus. Environ. Horiz. 2018, 4, 64-75.

Publisher's Note: MDPI stays neutral with regard to jurisdictional claims in published maps and institutional affiliations.

(C) 2020 by the authors. Licensee MDPI, Basel, Switzerland. This article is an open access article distributed under the terms and conditions of the Creative Commons Attribution (CC BY) license (http://creativecommons.org/licenses/by/4.0/). 